\title{
Correction: The Mechanical and Material Designs of Composite Ju|'hoansi Arrowheads
}

\author{
Courtney Archer, Iain Campbell, Fraser Cheyne ${ }^{\circledR}$, Amos Lim Jun Meng $®$, Csongor Senanszky, \\ Dimitrios Mamalis, Colin Robert $\mathbb{D}$ and Parvez Alam * $\mathbb{D}$ \\ School of Engineering, Institute for Materials and Processes, The University of Edinburgh, \\ Edinburgh EH8 9AB, UK; Carcher9@gmail.com (C.A.); iain.d.campbell1@gmail.com (I.C.); \\ frazch97@hotmail.co.uk (F.C.); amos.limjm@gmail.com (A.L.J.M.); csongor.senanszky96@gmail.com (C.S.); \\ dimitrios.mamalis@ore.catapult.org.uk (D.M.); Colin.Robert@ed.ac.uk (C.R.) \\ * Correspondence: parvez.alam@ed.ac.uk
}

Received: 10 October 2020; Accepted: 10 October 2020; Published: 13 October 2020

The authors would like to highlight the following correction to their published paper [1].

1. The following sentence from the original paper, "The first use of arrows in this region is recorded in cave paintings from between 60,000-64,000 years ago, while the first reference to the use of bone in arrows dates back to approximately 24,000 years ago" is incorrect. Instead, an up-to-date version should read, "The first use of arrows in this region was recorded through use trace studies on stone artefacts from between 60,000 and 64,000 years ago, while the earliest use of bone in arrows could date to approximately 70,000 years ago" [2].

2. The use of references [23] and [24] in the discussion of the original paper refer to aspects of cognition and evidence for early bow hunting in southern Africa, and not to the physical properties of ancient arrows as cited.

These corrections do not affect the scientific results reported, rather they are corrections of errors in our interpretation of the literature.

Acknowledgments: The authors would like to express their gratitude to Professor Marlize Lombard, University of Johannesburg, for alerting us to the errors highlighted in this correction, and for subsequent helpful discussions on the topic.

\section{References}

1. Archer, C.; Campbell, I.; Cheyne, F.; Meng, A.L.J.; Senanszky, C.; Mamalis, D.; Robert, C.; Alam, P. The mechanical and material designs of composite Ju|'hoansi arrowheads. J. Compos. Sci. 2020, 4, 139. [CrossRef]

2. Lombard, M. The tip cross-sectional areas of poisoned bone arrowheads from southern Africa. J. Archaeol. Sci. Rep. 2020, 33, 102477. [CrossRef]

(C) 2020 by the authors. Licensee MDPI, Basel, Switzerland. This article is an open access article distributed under the terms and conditions of the Creative Commons Attribution (CC BY) license (http://creativecommons.org/licenses/by/4.0/). 